This paper is forthcoming (2018) in a special issue on 'Reassembling the university' at the Globalisation, Societies and Education. Guest editors are Dr Chris Muellerleile and Professor Nick Lewis. It is the last author's version.

\title{
LinkedIn, platforming labour, and the new employability mandate for universities
}

\section{Janja Komljenovic}

Students, academics and university administrators are increasingly using and producing digital platforms. While there are many types and forms of platforms, social media are found to be particularly pervasive. This paper focuses on LinkedIn to start tackling the question of social media effects on higher education as a sector, its actors and the established social practices. LinkedIn is taken as a case largely because its business model moves beyond the passivity of advertising to its users towards actively structuring labour markets. LinkedIn is not only connecting students, graduates, universities, other training institutions and employers, but is organising social relations among them through its digital infrastructure. In this paper I first analyse how students, alumni and universities became prosumers of LinkedIn and what are LinkedIn's tactics to lubricate network effects in the sector. Second, I focus on how LinkedIn is changing conditions for academic knowledge production. I introduce the term 'qualification altmetrics' to argue that LinkedIn is building a global marketplace for skills to run in parallel to, or instead of university degrees. Finally, I consider the cultural, social, political and economic consequences for the higher education actors and the higher education sector more generally.

Keywords: Digital platform, higher education, labour market, employability, LinkedIn. 


\section{Introduction}

Not unlike many other fields and socio-economic sectors, higher education (HE) is also being transformed by digital platforms. Social media are a group of digital platforms, which are particularly pervasive in everyday practices of individuals and institutions. Academics engage with social media to communicate their research, to enhance their teaching practices, for general communication or personal promotion (Kjellberg, Haider, and Sundin 2016). Students use social media for personal reasons, but more recently for academic-related purposes, such as learning from academics and their writings on social media (Lackovic et al. 2017) or using social media that were incorporated in their study courses (Chawinga 2017). Finally, university administrators use social media to communicate with their audiences, such as students or parents (Voss and Kumar 2013), and to brand their universities in the student recruitment process (Rutter, Roper, and Lettice 2016). Most of these platforms seemingly offer their services free of charge, but regardless of their revenue streams, as new big data technologies that are plugged-in to universities and processes, they are changing the way the HE sector itself operates (Williamson 2018). The pertinent question is how exactly are they changing the sector? To tackle this question, I am particularly interested in LinkedIn as a social media platform that goes beyond advertising to its users and is purposefully structuring and restructuring the socio-economic relations of HE. Previous research has considered the use of LinkedIn by HE actors (Robertson and Komljenovic 2016), but it has not tackled the question of LinkedIn's effects on the sector and its social relations. This paper picks up where that research left off.

The increasing use of LinkedIn at universities coincides with the growing centrality of the employability discourse in the HE policy in the context of the knowledge based economy (Sum and Jessop 2013), in which universities are now 
explicitly expected to deliver graduate employment (Knight and Yorke 2003). Actors have become interested in graduate employability at numerous scales. At the supranational level for example, the Bologna Process in Europe aimed to enhance citizen employability through the HE reform (Dale and Robertson 2012). At the national level, governments in many countries have started to link graduate employability outputs of particular universities to their public funding like for example in the UK (DfE 2017). HE quality assurance bodies have started to link employability to quality assurance measures in various places including Denmark (The Danish Accreditation Institution 2013) or Croatia (Agency for Science and Higher Education 2017). At the institutional level, universities have focused on employability by expanding their career and employability-catering services for students and graduates, by including employability in their curriculums (Yorke 2006), and by adding graduate employability statistics in their marketing material (Chadha and Toner 2017). Finally, at the individual level, students and their parents are looking to analyse the available employability data when considering what and where to study (Komljenovic et al. 2018). For all of these actors at various scales, some of the biggest challenges are to find the best ways to boost graduate employability, motivate universities to accept responsibility for it, and finally, accurately measure graduate employability. While digital platform companies have a potential to offer new possibilities for measuring population data in relation to various sectors, LinkedIn is one of the key actors offering such possibilities for HE specifically for graduate employability.

The employability discourse in HE works well for LinkedIn and its expansion among HE actors. LinkedIn's strategies are yielding results as students are its fastest growing demographic (LinkedIn 2015) and LinkedIn hosts more than 25,000 university pages on its platform (ICEF Monitor 2015). Moreover, there is a mushrooming of 'how- 
to’ resources for universities to use social media for their marketing, branding and student recruitment (e.g.: Shih 2011; Kelly 2016), as well as a plethora of material for students on career advice and the use of social media (e.g.: Schepp and Schepp 2012). In such guides, LinkedIn is unique as the most professional of the social media platforms; and the only one dedicated specifically to the labour market and thus the graduate employability.

In terms of the policy presence of the employability discourse in HE, one of the most significant questions is, what are the consequences for the sector and society at large. Authors identify effects such as utilitarian shift in the curriculum, unbundling of the curriculum and university service, and consumerist student behaviour (e.g. Boden and Nedeva 2010; McCowan 2017; Nixon, Scullion, and Hearn 2016). While recognising these effects, there is a lack of research on the intersection of $\mathrm{HE}$, employability and digital platforms as a complex interplay between technical architectures, business models, and mass user activity. What do digital platforms do to HE; and more specifically, how does LinkedIn translate the mandate to produce graduate employability and HE?

In what follows I will first theoretically explore digital platforms, followed by a general introduction to LinkedIn, and my methodological approach to studying the firm. In the following section I analyse the processes of LinkedIn actively targeting and engaging HE actors and turning them into prosumers (Ritzer and Jurgenson 2010). I then investigate LinkedIn's construction of the marketplace for skills and how this is reassembling the academic knowledge production. In the final section I turn to the larger consequences for the HE sector in terms of markets, politics and building of the global super-structures. 


\section{Digital platforms}

At their most basic, platforms are defined as digital infrastructures that allow two or more groups to interact by bringing together various users, such as “customers, advertisers, service providers, producers, suppliers and even physical objects” (Srnicek 2017, p. 43). For example, Google search engine connects advertisers, content providers and individual users (ibid). There are various types of platforms and some authors have provided useful classifications based on the type of the firms (ibid), the type of mediation (Langley and Leyshon 2017), or the type of the function within a process, like the knowledge production (Robertson 2019). For the purpose of this paper, I am interested in the for-profit platforms that became the central infrastructure of the economic and social life (Mackenzie 2018); and specifically in LinkedIn as an example of such platforms.

The first essential characteristic of platforms are 'network effects'. This refers to the dynamic spiral growth in which the platform becomes more valuable for its users the more numerous and active they are (Srnicek 2017). Platforms construct and lubricate network effects by collecting and manipulating ever larger amounts of data, which they manage to do through the participatory economic culture (Langley and Leyshon 2017) associated with the 'Web 2.0'. Web 2.0 refers to a collaborative use of the Internet and the production and modification of online content by users (Couldry and van Dijck 2015). Network effects tend to encourage monopolies because the more users a particular platform acquires, the better or more 'accurate' the meta data derived from those users becomes. Authors have coined various concepts to describe particular aspects of such user behaviour like prosumption (Ritzer and Jurgenson 2010), coproduction (Prahalad and Ramaswamy 2004), productive publics (Arvidsson and 
Peitersen 2013) and peer-to-peer (Oram 2001). The common dynamic of all of these concepts is the benefit of network effects.

The second essential trait is that unlike many conventional firms, platforms coordinate multisided markets (Andersson Schwarz 2017), meaning that platforms have significant pricing power over both suppliers and consumers. Langley and Leyshon (2017) point out that platforms organise market encounters in the market-making processes (Çalışkan and Callon 2010) by bringing together actors that would otherwise not meet and thus lubricate exchanges that would otherwise not happen. However, as I will show later, platforms also structure other market-making processes beyond market encounters, such as the market order, rules and institutions.

The third characteristic of platforms is that they are a new kind of firm operating in capitalist markets and striving for profit (Srnicek 2017). Platforms are not just enabling new modes of mediation, but are affording new "kinds of work and commodities, new kinds of firms and production, and new markets for exchange” (Muellerleile 2017). Platformization is thus closely entangled with capitalization - the process of turning something into capital (Muniesa et al. 2017) and are infrastructural sites of accumulation, growth and revenue (Mackenzie 2018). The business model of digital platforms is to grow fast in scale and find ways to monetise and profit from data later (Fourcade and Healy 2017). As users and data are continuously value-producing as information providers, platforms condition user behaviour to attract users and their attention. Data can be re-produced, re-packaged and capitalised upon infinitely (Fuchs 2009).

Finally, the infrastructural quality is important in that platforms are programmatic and technical, prescribing what is possible through the code and algorithms (Helmond 2015). Like much infrastructure, platforms are often promoted as 
neutral and objective, but they in fact "actively induce, produce and programme circulations” (Langley and Leyshon 2017, p.19). In this sense, the code and algorithms becomes important because they are products of, but also productive of social, political, economic and cultural effects (Williamson 2015). I now turn to LinkedIn and set the groundwork of how it is productive of particular meanings and framings of graduate employability and university qualifications.

\section{Studying LinkedIn}

Social media firms are seen as representative platform operators through which platformization processes could be studied (Helmond 2015). I focus on LinkedIn for the following reasons. First, LinkedIn is one of the biggest social media platforms and among 30 top sites on the whole Web with respect to number of visitors and clicks (based on Alexa.com). Second, LinkedIn benefits from and contributes to the employability discourse - one of the key policy aims governing the HE sector. In this context, it became big enough to track attention among important policy actors, such as the World Economic Forum that relies heavily on LinkedIn's data in its latest Human Capital Report stating that official and national statistic do not provide satisfactory information anymore (World Economic Forum 2016) . Third, LinkedIn is specifically targeting the HE sector with developing particular features that are generated explicitly for students, graduates and universities (LinkedIn 2016). Finally, previous research revealed that universities became reliant on LinkedIn, and especially in their work with alumni (Robertson and Komljenovic 2016).

LinkedIn started as a digital network of people sharing their professional experience via an Internet page in 2003. By 2011, when it became a publicly traded company, LinkedIn had attracted 145 million users from 200 countries and territories; and operated in 17 languages. By 2015 it boasted over 400 million individual and 
institutional users; which resulted in an annual net revenue of \$US 3 billion and registered profits of $\$ 780$ million in 2015 on an EBITDA ${ }^{1}$ basis (LinkedIn Corporation 2012, 2016). In 2016, Microsoft acquired LinkedIn for $\$ 26.2$ billion, which was the third largest acquisition in the history of the technology industry (The Economist 2016). LinkedIn became a major 'big data' company mediating a fine line between free services for users to keep their interest and scale; and commodified services through which it makes profit. LinkedIn is selling a variety of data-generated commodities that are grouped into three revenue streams (see Table 1). Its fastest growing set of products are 'talent solutions' (see Figure 1), which is where LinkedIn is at its most innovative. Even after the acquisition by Microsoft, LinkedIn seems to be doing well in terms of attracting new members which are now more than half a billion (Darrow 2017); and creating profits mostly from talent solutions (Novet 2018).

Table 1. LinkedIn services as of 2015.

\begin{tabular}{|c|c|c|c|c|}
\hline \multicolumn{2}{|c|}{ "Free solutions" } & \multicolumn{3}{|c|}{ "Monetised solutions" } \\
\hline $\begin{array}{l}\text { "Stay connected } \\
\text { and informed" }\end{array}$ & $\begin{array}{l}\text { “Advance my } \\
\text { career” }\end{array}$ & “Talent solutions” & $\begin{array}{l}\text { “Marketing } \\
\text { solutions” }\end{array}$ & $\begin{array}{c}\text { "Premium } \\
\text { subscriptions" }\end{array}$ \\
\hline $\begin{array}{l}\text { "Feed, Me, } \\
\text { Messaging, My } \\
\text { network \& search, } \\
\text { People you may } \\
\text { know, Pulse, } \\
\text { Influencers, } \\
\text { Groups, } \\
\text { Slideshare, } \\
\text { LinkedIn Lookup, } \\
\text { Address Book } \\
\text { Importer, } \\
\text { Publishing } \\
\text { Platform” }\end{array}$ & $\begin{array}{l}\text { “Jobs, Job Search } \\
\text { App, Company } \\
\text { Pages, University } \\
\text { Pages, Who’s } \\
\text { Viewed your } \\
\text { profile / How you } \\
\text { rank, Rich media / } \\
\text { Skills / } \\
\text { Endorsements” }\end{array}$ & $\begin{array}{l}\text { "Hiring: LinkedIn } \\
\text { corporate solutions } \\
\text { (Recruiter, } \\
\text { Referrals, Job } \\
\text { slots, Recruitment } \\
\text { media, Career } \\
\text { pages), LinkedIn } \\
\text { job postings, Job } \\
\text { seeker, Recruiter } \\
\text { lite; Learning and } \\
\text { development: } \\
\text { Lynda.com” }\end{array}$ & $\begin{array}{l}\text { “Sponsored } \\
\text { updates, LinkedIn } \\
\text { ads, Elevate, } \\
\text { Sponsored } \\
\text { InMails, Display } \\
\text { ads, Ads API” }\end{array}$ & $\begin{array}{l}\text { "Professional / } \\
\text { individual } \\
\text { subscriptions, } \\
\text { Sales solutions } \\
\text { (Sales Navigator), } \\
\text { Profinder” }\end{array}$ \\
\hline
\end{tabular}

Source: (LinkedIn Corporation 2016, pp 5-6).

\footnotetext{
${ }^{1}$ EBITDA are "earnings before interest, taxes, depreciation, and amortization (used as an
} indicator of the overall profitability of a business)” (Oxford Dictionary 2016). 
Like most digital platforms, LinkedIn’s does different things for different customers. Amongst these are: a service commodity for individual or institutional users who pay subscription fees; a marketplace for labour; a platform for marketising trust, legitimacy, or recognition; a benchmarking and ranking company; a big data repackaging service; and so on. LinkedIn’s core business nevertheless seems to be digitally structuring the labour market and selling data products related to employability (see Figure 1). An important part of the labour market are HE diplomas and skills certificates. Therefore, it is no surprise that universities are one of the six core elements in the LinkedIn's remarkable endeavour - the economic graph, which encapsulates LinkedIn's representation of the world economy and its role within it (Weiner 2012).

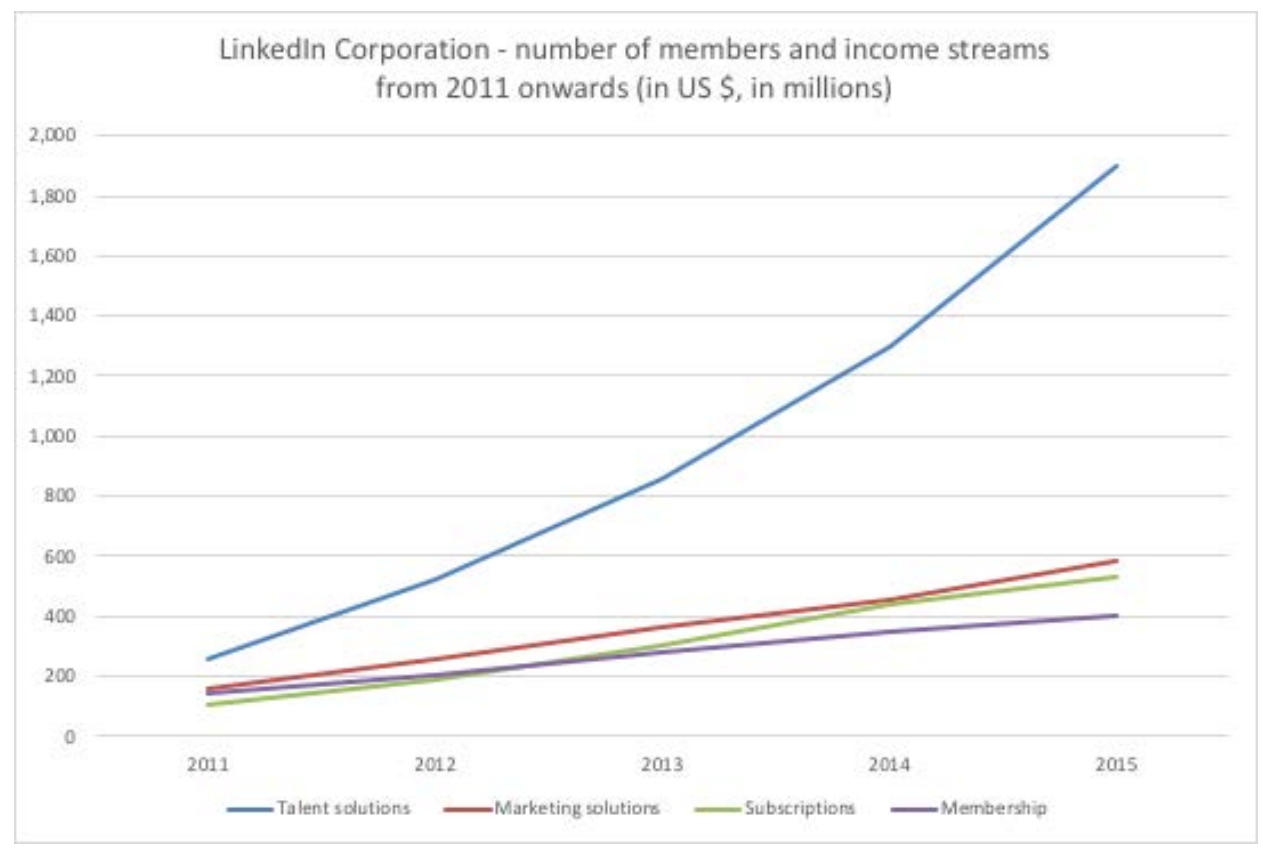

Figure 1. The number of users of LinkedIn from 2011 to 2015 and the income streams. Source: Created by the author of this paper based on data from LinkedIn's annual reports (LinkedIn Corporation 2012, 2013, 2014, 2015, 2016). 
LinkedIn’s income (Figure 1) from subscriptions and marketing solutions shows a rather stable growth corresponding with the growth of its users (membership). Talent solutions, however, grew faster, which makes LinkedIn a very different company to other digital platforms and especially social media platforms. Most of Google’s, Facebook’s and Twitter’s income is from advertising (Fourcade and Healy 2017), making these companies invest in data manipulation and user behaviour in relation to selling commodities to users and tailored product exposure (Srnicek 2017). LinkedIn, on the other hand, constructs its platform in order to sell user data for the labour market in various repackaged forms (see 'talent solutions' in Table 1). As I will show later, it is experimenting to find best and novel services supported by collected data; and developing algorithms to make this service grow.

Methodologically, constructing a case study of the LinkedIn platform in relation to the HE sector has involved close documentary analysis of various materials. I collected publicly available documents about and from LinkedIn, namely news reports, LinkedIn webpages, all available company annual reports (which were from 2011 to 2016), documents related to a class action against LinkedIn in the USA from 2013, and LinkedIn's own news, press releases and promotional material. The collected empirical data was supplemented with findings in relation to LinkedIn from the large research project about market-making in HE (Komljenovic and Robertson 2016). Twenty-eight semi-structured interviews with managers and assistant managers across different units of university administration at two UK Russel Group universities were conducted between March and June 2014. Thick description (Ponterotto 2006) of the case was used as a step in the analysis and for the purpose of abstracting and identifying key processes of LinkedIn's work in the HE sector. Three groups of processes were identified, to which I turn next. First, network effects among HE users of LinkedIn; 
second, changing conditions for academic knowledge production; and finally, introducing measurement and market-making processes in expansion of LinkedIn's platform and building of the global super-structures.

\section{Networking into big data}

This section focuses on digital platform dynamics and particularly on the ways platforms establish and lubricate network effects. I argue that the HE sector is no exception in engaging with digital platforms as its actors have become "prosumers" (Ritzer and Jurgenson 2010) and as such are enabling the accelerating growth of the platform. I develop my analysis in two distinct, but related moves. First, I examine how LinkedIn is engaging HE actors and turning them into prosumers. Second, I explore how LinkedIn is experimenting with HE specific services on its platform to motivate network effects.

\subsection{Higher education prosumers}

Table 2 summarises what products and services were on offer to the HE actors in the time of writing this article; albeit LinkedIn started to target its products and services specifically to students and universities around 2012 (Fathom 2012). Most of these services are free for users and are network-based in that the collected user data is manipulated and used in various calculations and algorithms, which 're-package' data back into products for users to encourage even bigger use of the platform. These network effects thus benefit the users while at the same time allow LinkedIn to push out competition in its monopolising tendencies to capture the global digital labour market. While employers increasingly rely on social media in their recruitment processes, LinkedIn is the dominant platform (Jobvite 2016). Network effects, specifically monopolising tendencies, tie the customers to the platform so that they do not leave for 
competition while LinkedIn's monopoly is strengthening.

Table 2. LinkedIn services and products for HE as of 2017.

\begin{tabular}{|c|c|}
\hline \multicolumn{2}{|c|}{ LinkedIn's services and products developed for students and universities } \\
\hline Students & Universities \\
\hline $\begin{array}{l}\text { - Searching universities based on career outcomes of } \\
\text { their graduates } \\
\text { - Building one's professional brand (author's note: } \\
\text { meaning personal profile) } \\
\text { - Building a student profile } \\
\text { - Tailoring a profile to one's goals } \\
\text { - Finding a student job or internship } \\
\text { - Networking on LinkedIn } \\
\text { - LinkedIn for Students: educating students for } \\
\text { creating best LinkedIn profile } \\
\text { - Student app targeted specifically to soon-to-be } \\
\text { graduates } \\
\text { (- Cancelled solutions on searching universities: } \\
\text { university rankings, field of study explorer, } \\
\text { university finder, personal decision board) }\end{array}$ & $\begin{array}{l}\text { - Student profiles: students of the particular } \\
\text { university can showcase their experience, courses, } \\
\text { and projects in order to be discovered in recruiter } \\
\text { searches } \\
\text { - Alumni tracking: universities can discover paths } \\
\text { and contact information of their alumni; and find } \\
\text { good examples of alumni to show to students or for } \\
\text { promotion } \\
\text { - Groups: universities can use groups for discussions } \\
\text { and communications with alumni and students } \\
\text { - University pages: universities to brand and } \\
\text { promote themselves } \\
\text { - LinkedIn Showcase Pages (creating customised } \\
\text { individual pages within the site) } \\
\text { - Students jobs pages: motivate students for work } \\
\text { experience } \\
\text { - Universities can use advanced search for people } \\
\text { and contacts } \\
\text { - Universities can use LinkedIn user profiles in } \\
\text { student recruitment processes } \\
\text { - Key products to be: alumni tool, students jobs } \\
\text { portal, student profiles, university pages } \\
\text { - LinkedIn merged 'company pages' and 'university } \\
\text { pages' in early } 2017\end{array}$ \\
\hline
\end{tabular}

Source: Created by the author of this paper based on data from: Baker (2015), ICEF Monitor (2015), LinkedIn Corporation (LinkedIn Corporation 2013, 2016) and Pace (2017).

Students are encouraged to use LinkedIn platform throughout the entire cycle of studentship. Before enrolling, potential students are encouraged to use LinkedIn in their decision-making about where and what to study. As students, they are encouraged to create their own user profiles and regularly update them. In their final year, students are offered a specific 'student app', which on a daily basis suggests types of jobs to students based on their education, offers information on the companies which have hired graduates from their university, enables viewing the profiles of alumni graduating in the same field, and advertises jobs appropriate for their fields and years of study (Yu 2016). 
Finally, as alumni they are encouraged to keep their profile updated or to create one if not so done before, post updates about themselves, their opinions, news and other information, network in their groups, communicate with the groups and other users, read stories posted by other users and opinion leaders, follow their chosen sector, and follow their own user analytics. Crucially, students have been LinkedIn’s fastest growing demographic for some years now (LinkedIn 2015).

Universities are encouraged to use the LinkedIn platform in relation to various processes revolving around the employability discourse. First, in relation to their own operation, they are advised to use the 'university pages', where they can showcase their university brands. Second, they can use features called 'alumni groups' and 'student groups' to communicate with their students and alumni. Finally, they are advised to encourage students and alumni to create user profiles and to offer advice on how to create good profiles, called 'personal brands'. LinkedIn thus promotes universities to use the platform themselves, but also to motivate their constituents to use it too and teach them about best practices of the platform use.

The flagship LinkedIn product in relation to universities is the before-mentioned 'university pages', which is a combination of university-generated information about itself and LinkedIn-generated data about employability figures of their university's graduates. It is intended to be used by prospective students in their HE decision-making; as well as by anybody judging universities in relation to employability of their graduates (such as governments or HE funding authorities). University pages offer the following search possibilities:

Key search criteria available include the ability to search by location, course, skills, employment and how you are connected on LinkedIn. There is also a very helpful key word search. The results are then mapped below with all relevant LinkedIn profiles and useful individual summaries (Cannon 2015). 
This way LinkedIn extends the dimensions in which universities are being evaluated to employability, careers and employment-related aspects of HE. Interestingly, universities only have partial control over branding on the university pages as their own page is a hybrid of information generated by themselves and LinkedIn algorithms. There is thus an element of standardisation which engenders university competition.

The empirical data collected at the two British universities show they both indeed make use of the LinkedIn’s services and products (see Table 3). LinkedIn was the key source of information about their own alumni. Both institutions relied on their 'LinkedIn groups' to communicate with their alumni, and have turned away other firms offering to construct or maintain alumni directories or build online communities. Moreover, university administrators used LinkedIn for promotion and branding of their universities and finally, for their own work-related purposes.

Table 3. Uses of LinkedIn by Curie and Austen universities as of 2014.

\begin{tabular}{|c|c|l|l|l|}
\hline \multicolumn{5}{|c|}{ Uses of LinkedIn by two case universities } \\
\hline $\begin{array}{c}\text { Promotion and } \\
\text { branding }\end{array}$ & \multicolumn{1}{|c|}{ Communication } & \multicolumn{1}{|c|}{ Database } & \multicolumn{1}{c|}{$\begin{array}{c}\text { Cooperation and } \\
\text { work }\end{array}$} \\
\hline $\begin{array}{l}\text { - University pages } \\
\text { - University search } \\
\text { - University ranking }\end{array}$ & $\begin{array}{l}\text { - Alumni group } \\
\text { - Students career group } \\
\text { - Other interest groups }\end{array}$ & $\begin{array}{l}\text { - Extract data from } \\
\text { LinkedIn into university } \\
\text { llumni database }\end{array}$ & $\begin{array}{l}\text { - Networking } \\
\text { - Looking for } \\
\text { information on people } \\
\text { and companies }\end{array}$ \\
\hline
\end{tabular}

The prosumer dynamic in the case of LinkedIn and the HE sector works first by developing particular targeted features useful to specific user groups to engaging them with the platform. Second, automatically created institutional profiles makes universities populate their pages sooner than they would on their own; and to a bigger scale. Such is the case with the 'university pages' as will be explained below. Finally, building on central policy aims like graduate employability and working with 
institutions like universities, speeds up the temporality of the prosumer dynamic and makes it relational. Universities benefit from using the platform to enhance employability of their graduates and collect 'free' data for their own strategies; while the platform can build on the established relationship between universities and its students as universities become platform’s promoters among its constituents.

\subsection{Experimenting with services}

LinkedIn has been open about its strategy to specifically target HE as a sector and its actors. When asked about their motivation for launching an education platform, Charles Hardy, LinkedIn’s ‘education engagement lead’ stated in his 2015 interview:

There are three pieces here. Number one is growth - we are getting more members from these activities and like a bank if you get them young hopefully they will stay. The education platform really is a growth strategy for LinkedIn. The second strand comes from how the growth in members feeds other parts of our business. So as we grow our members and they add more data, it helps grow our recruitment talent solutions business, drive our marketing solutions business and all these different elements have monetisation and are revenue generating. Our clients looking to target the youth audience also benefit over time as our youth data becomes ever richer. (...)The third element is an altruistic one. Essentially we asked ourselves "how can we help young people to start their careers? How can we leverage LinkedIn data to help with this sometimes hard and complicated process?" (Cannon 2015).

A key component of LinkedIn's strategy vis a vis the HE sector is experimentation. This is not unusual as the platform business model works with future facing processes of valuation and capitalisation (Langley and Leyshon 2017), namely collecting as much data as possible as soon as possible, and find ways to profit from them later (Fourcade and Healy 2017). Within this, platforms have to find ways to attract users by creating and useful services. They are found to model user behaviour (Langley and Leyshon 
2017). Such dynamic processes are also common in the context of market-making more generally in that active market makers constantly find different ways, tools and institutions to frame and order markets (Çalışkan and Callon 2010). Testing and adjusting, developing and cancelling products, rules and institutions are part of marketmaking dynamics.

LinkedIn is now organising the events for the HE sector to collect input on further developing the platform (Musson 2016); and also visiting universities as told by one of the interviewees of the two British universities:

They've [A/N: LinkedIn] created a new way of slicing their data that's particular to HE. They're starting to create posts [A/N: hiring workers] who are coming out to talk to universities, to career offices, alumni offices, to tell us about all the features that can be used. They are starting dialogues with us what other software we would like. They haven’t asked us to pay for anything yet, but it’s absolutely coming (Alumni office, 25 March 2014).

Such experimental and dynamic nature are evident in the before-mentioned most prominent feature of LinkedIn’s platform for universities - 'university pages'. It was launched in August 2013 and in 2014 LinkedIn added the possibility for alumni to comment on their university (De Wit 2014), which has been removed in 2016 (Pace 2017). Moreover, LinkedIn merged ‘university pages’ and ‘company pages’ for universities. 'University pages’ were created automatically by LinkedIn to showcase universities in their role although universities could require for their pages to be set up; while 'company pages' were created by universities in their role as employers. After LinkedIn merged these two pages, some features were kept and others were cancelled. In what is sometimes called a "freemium" model, the basic university page is free for universities, but an upgrade with 'career pages' is monetised since the merger of the two pages: 
The Life and Jobs tabs of a University Page are paid features known as Career Pages that help engage potential employees with your mission, opportunities, and culture through customizable features and dynamic content (LinkedIn 2017a).

The price list is not freely available and universities need to contact LinkedIn to enquire. This is merely one example of monetising services besides the data-generated products that LinkedIn sells.

Further experiments are seen in features like the 'education hub page', 'decisions boards', 'field of study explorer', 'university finder' and the 'university rankings'. These are the services that LinkedIn had created and later cancelled without much explanation and instead built the ‘student app’ (Joly 2016).

The nature of prosumerism where on the one hand we witness a spiral growth of using and producing data, and on the other hand a complex dynamic of experimenting with what works best, is in itself building particular kind of infrastructure, devices and markets that reframe meanings and value in the sector - to which I turn next.

\section{Platformizing qualifications and skills}

In this section I focus on the categorisation of skills, qualifications, people, institutions and employers into specific forms of connection on the platform. I argue first that by constructing a marketplace for skills, LinkedIn enables and lubricates particular multisided markets through its platform. Second, that by doing this, it is re-making the way knowledge bearing bodies are produced and credentialised, as well as contributing to the unbundling of conventional university qualifications into new and dynamic digital profiles.

\subsection{Constructing a marketplace for skills}

LinkedIn reframes labour markets as both global and far more fluid than before. The 
new global labour market (in effect imagined as a configuration of LinkedIn members, jobs, companies, knowledge, and education providers) is increasingly seen by LinkedIn and others as built from blocks of variously qualified, certified, and valorised skills. While formal education is still positioned as crucial, it is also paralleled to the acquisition of credentialed skills. These may be provided by any provider, rather than just nationally bound and quality-controlled universities and education institutions, or even acquired by experience. There is now a multitude of providers of various distance learning opportunities for particular skills; but this is yet an emerging market that must be made, framed and ordered by accreditation agencies and mediators who create demand, make connections, establish trust and valorise. LinkedIn works with data freely given to it by its prosumers to make a valorisation and certification markets of skills, position itself to be a leading actor in these markets, and create the global labour market - all of this simultaneously.

LinkedIn allows users to self-assign particular skills or have an algorithm assign them to a user; and then invites individuals connected to the particular user to endorse them for the particular skill. The automation of endorsing other users for particular skill has existed for a number of years. When a user logged into the platform in the past, they were offered to click 'yes’ or 'no' for a particular skill to be assigned to a particular person. Today, users can still endorse others, but need to visit their profiles specifically. The user is supposed to judge other users based on personal experience with them. LinkedIn's platform then showcases skills that are assigned to particular people in their digital profiles. Next to the skills, there is a number, showing how many users have confirmed that an individual indeed holds a particular skill. This system could be understood as 'qualification altmetrics' in that instead of possessing particular diplomas or certificates, skills acquired by experience or in any other way can be confirmed by a 
person's digital network and calculated by the platform's algorithms. Users can also receive general recommendations to their profiles by other users.

By working with both quantified employability data and the qualitative comments of users, LinkedIn is able to reaffirm skills as key for individual employability as well as the wider economy. LinkedIn's framing is endorsed by the World Economic Forum, which states:

\begin{abstract}
Whereas employers and job seekers generally rely on formal education degrees and job titles to determine fit for a role-and national and international statistics agencies similarly capture a country's human capital endowment in this way-the LinkedIn data reveals that understanding an economy's human capital base at the actual skills level is crucial because formal qualifications alone are often insufficiently meaningful and job titles may imply very different skills requirements in different industries and geographies (World Economic Forum
\end{abstract} 2016, p. 18).

LinkedIn is not only a place where employers can shop for labourers, but is in itself becoming a marketplace for skills. It could conceivably begin to create structures of skills, credentials and jobs by matching skill sets to certificates, where they were acquired, and what is required for specific jobs and might lead to success in the global labour market. It holds the data to be able to act in this way, reworking and commodifying in new ways relationships among universities, other training institutions, students, graduates and employers. LinkedIn could possibly qualify and valorize each of these elements, and is already doing so at some level. The platform is using rich, freely obtained data, search engines, algorithms, and the fear that market participants cannot afford not to be involved, to create virtual circuits that enclose the global labour market and constitutive elements. The possibilities for innovation around new kinds of future services with data are immense (Fuchs 2009). 


\subsection{Platformizing and capitalizing on training for skills}

LinkedIn has recognised the potential of matching profiles with skills and acquired a company called Lynda for \$1.5 billion in 2015 (LinkedIn Corporation 2016). Lynda was a well-established provider of online learning and training. Unlike the massive open online courses, Lynda was charging for access to its online content. The move positioned LinkedIn to enter the skills training market and has raised much interest and debate at the time:

LinkedIn is painting a scenario in which you search for a job, see the skills required for that job, and then are directed to a course from Lynda.com that will train you in those skills. Alternatively, a recruiter could search for available candidates based on the courses they've taken. You can already add courses to your profile, but courses endorsed by LinkedIn may carry more clout (Wagner 2015).

LinkedIn’s involvement with Lynda seems to signal participation in education provision as LinkedIn has fast developed its 'Learning' service, which recommends and offers particular courses that LinkedIn's algorithms calculate are best for a person's profile. At the time of writing this article, LinkedIn had a section at the user profile called 'add new skills with these courses', which is promoting personalised courses offered by LinkedIn to a particular user. They span from generic to specific skills courses. An example of courses targeted at generic skills that was offered to my personal profile was 'communicating with confidence'. The course promised to provide tools, strategies and tips for effective communication. An example of courses targeted at specific skills was 'gamification of learning', which promised to train in gamification as an instructional design. This way LinkedIn is indeed promoting its own courses over other providers', as it was speculated in time when LinkedIn bought Lynda. At the time of writing this article, these courses did not seem to be promoted as replacing university 
degrees. Instead they were tailored to all user profiles and portrayed as most 'indemand' skills that would help towards the attractiveness of an individual on the labour market. Thus LinkedIn is itself advancing a disassembly of knowledge or cognitive capacities to skills in relation to the labour market needs and then reassembling them back into a user profile. Therefore it is monetising the 'skills gap' that itself constructs.

The acquisition of Lynda potentially makes LinkedIn a direct competitor to those education and training institutions that it is also helping to brand and promote; and makes it a competitor in a market that it is constructing and qualifying. LinkedIn is thus a platform that enacts multi-sided markets by bringing together various different markets and market actors and enabling multi-sided market exchanges between them. This represents new reality for universities and established practices of academic knowledge production, to which I turn next.

\section{Politics, markets and data}

So far I have analysed the HE prosumer dynamics of LinkedIn and the reframing of particular ideas related to employability and skills. I have argued that LinkedIn provides and uses its infrastructure to expand data markets enclosing and capturing data from the HE sector, promote the employability role of the university and lubricate the orientation towards skills in the labour market instead of or in parallel to university degrees. In this final section I focus on what are the cultural, social, political and economic consequences for the HE sector in terms of socio-technological nature of algorithms using the collected big data from HE actors.

\subsection{Employability discourse in numbers, algorithms and visualisations}

The HE policy aim of employability is becoming lucrative for LinkedIn through its materialising of the employability discourse in numerical measurement and aesthetically 
pleasing visualisations, all supported by algorithmic processing. First, LinkedIn is showcasing aggregated data on graduate employability in many forms and venues: at university pages, which were already described. Second, the aggregated data is used in numerous studies that LinkedIn now routinely produces and publishes, which are picked up in news. Relevant studies include: the most promising jobs in a particular year, top skills that employers look for in a particular year, most popular entry level jobs in a particular year and many others. The employability data that LinkedIn produces can be sliced for any variable, such as the sector, level of education, country, company, university, or job. For example, LinkedIn offers information on a job 'University lecturer' and it provides a simple infographic on 'top companies' that employ for this job, 'top universities' that employees with this job come from, 'top industries' that they are employed in and 'top locations' where they are based. In addition, there is a display of 'top skills' that they have (LinkedIn 2017b). Such information are provided for a variety of jobs. This way LinkedIn provides rich metrics and data that is much sought after by policy makers and general public discourse.

Visualising data has a potential to shape behaviours, attitudes and norms and structure the social world (Williamson 2018); while algorithms are a product of, but also productive of the social, political, economic and cultural life (Williamson 2015). While LinkedIn is picking up on employability discourse, it is at the same time structuring it in a particular way. Consequently, it is doing cultural work in changing meanings of what is a successful graduate, what is a good university, what is a desirable job, and the like. Thus LinkedIn is building a particular kind of employability within the employability discourse. Previously mentioned experimental features like the ‘university ranking' should not be ignored. Even though this particular experiment has 
been cancelled, it is still possible to glean an understanding of LinkedIn's strategy looking closely.

LinkedIn introduced notions of 'relevant' graduates, 'desirable' jobs and ‘desirable’ employers (LinkedIn 2014). This was related to how many graduates of particular universities and particular programmes are employed at specific employers and their position in LinkeIn’s employer ranking. Other factors potentially affecting employability, such as personality, family connections, rank of the university one has graduated from, or socio-economic status were not scrutinised in the LinkedIn algorithms that measure universities’ quality. Universities are judged as well as build their brands around graduate employability, which brings new power relations into HE competition and incentivizes particular kinds of competition.

'University rankings' did not bring only new ideas on particular kinds of successful graduates based on employability measures, but also ideas on particular kinds of successful universities. Unlike the focus on research outputs in other university rankings (Hazelkorn 2009), the standards for quality in Linkedin's ranking were the careers of graduates, which were valorised by LinkedIn's ranking algorithm. They were therefore determined differently than those set by national quality assurance agencies, which tend to cover a range of input and output indicators that stand as proxies for research output, teaching quality, and infrastructural resources. It was also not clear what exact criteria were used in LinkedIn's algorithms. The elements included in the algorithm had been made public (LinkedIn 2014), but LinkedIn has not explained its exact methodology or subjected it to the modifications that public scrutiny might bring. Although 'university rankings' were cancelled, they were changing the focus on 'what counts' in the HE sector and imaginations of the future towards a more utilitarian notion of a university degree couched in the discourse of employability. 
In all of this we witness a double dynamic of platformization and capitalization at the same time. The ordinal numbers that LinkedIn publishes by means of transforming big data into meaningful meta-data are part and parcel of platform capitalization (Mackenzie 2018). By communicating numbers on people, jobs, skills, universities and employers, LinkedIn is gathering things and people around itself as well as it enables its potential to grow. LinkedIn claims the expertise in the conceptualisation of employability through the ownership of the infrastructure required to calculate big data around it. It has built a geo-political superstructure with market monopoly tendencies, to which I turn next.

\subsection{Geo-political superstructures}

At the macro geo-political level only few companies dominate the platform ecology and had created digital superstructures that interplay and depend on each other. They at the same time provide free service for users, collect and monetise data, and feed it back in various governing devices such as user analytics. This enables novel forms of synergy for those that own and control this data as one and the same company is in charge of the data that would otherwise be separated if it weren't for platforms and their integration. Companies with such global dominance can use intelligence from one sector to develop data services in another and consequently collect even more data and even more value (Andersson Schwarz 2017). LinkedIn has clearly done so as exemplified in the above quote from Charles Hardy. It has targeted the HE sector and its actors to spiral its growth in the labour market services.

The dynamic of experimenting with services, which was described above, now encompasses more sectors after Microsoft's acquisition of LinkedIn. Not only is LinkedIn showing monopolising tendencies within the digital global labour market, but this acquisition also points to Microsoft's tendencies to monopolise various sectors and 
industries. The spill-over effect in this case is Microsoft's latest service called 'resume assistant' that integrates data from LinkedIn with Word software to help users write their resumes for job applications. This feature pulls data from LinkedIn to advise the Microsoft Word user on which skills are most popular for the job they are applying for or how professionals in that sector made their resumes (Nieh 2017). It is not yet known what does this kind of platform growth and increasing interplay between platforms and global providers mean for universities and academic practices, but it is safe to say that university graduates and consequently universities are increasingly caught up in the platforms’ logic.

A twofold logic of platforms is at work here, namely the micro-level technocratic control and the macro-level global monopolisation with variety of generative outcomes that emerge between these levels (Andersson Schwarz 2017). At the micro-level, LinkedIn is technically enabling and lubricating particular elements of education and knowledge with its infrastructure (such as promotion of skills in parallel to or instead of university diplomas). At the macro-level, it is dominating the global digital labour market and constructing it in a specific and particular way, which is on the one hand based on social network logic (such as with the qualification altmetrics) and on the other hand based on data materialisation (such as providing data and indicators for public policy). This way, issues of profiting arise simultaneously with controlling and structuring user behaviour and the labour market elements.

Questions about data and algorithms used for controlling and classifying user behaviour on platforms tend to stay out of debates about markets and data, dismissed as technical and micro issues. Fourcade and Healy (2017) make a case that market actors use the enormous amounts of data and construct algorithms that are seemingly objective and benefitting users, however, they are reproducing structural social inequalities. Thus 
the questions of how data are used and what kind of algorithms are built, are in fact political and macro issues as they structure the wider social and economic order. It will therefore be important to see if LinkedIn's algorithms will be able to contribute to more equal opportunities in the labour market or will they reproduce existing inequalities and bias, which is found in more traditional recruitment processes.

\section{Conclusion}

The aim of this paper was to analyse social media more generally and LinkedIn more specifically. It considered the ways they impact HE actors, academic practices and the HE sector more generally. It targeted a gap in literature at the intersection of social media platforms and the changing political economy of HE. First, it argued that various HE actors are becoming prosumers as they are entangled in data markets, and as the data they produce is monetised and repackaged to become governing devices for their own sector. Second, it argued that the platforms materialise data and by doing so reframe meanings in the HE sector about quality of universities and degrees; graduates and their diplomas; and skills in relation to employability. Finally, it argues that platforms with opportunities and restraints of its infrastructure change the conditions for academic knowledge production and credentialisation. Universities find themselves in a new environment that marries market competition and graduate employment with a focus on skills. The translation of knowledge at the HE level to skills is changing the very nature of HE and the project of the university (Ashwin 2015). This further lubricates an already strong policy and public focus on graduate employability and places universities in a different position to prove their place in society. The article introduced the concept of 'qualification altmetrics', which benefits from network effects to valorise individuals' skills and qualifications relevant for the labour market as opposed or in parallel to formal university degrees. 
The paper showed how the presence of social media platform such as LinkedIn are creating new realities, in which HE actors must operate. It highlights the new use values that LinkedIn provides for HE actors; the new scales, scope and dimensions that digital platforms and data bring; and LinkedIn’s growing potential to use big data to expand, structure and control different marketplaces into which it is linking universities. Moreover, it elaborates how these markets profit from and contribute to the promotion of the employability discourse as well as a focus on skills. It demonstrates clearly how the digital economy is being entangled in the material HE economy, to such an extent that it is now structuring it. The paper reveals LinkedIn to be a highly prominent architect and beneficiary of this process.

By breaking down both, the labour market needs and education qualifications; and reinforcing a focus on skills, LinkedIn is able to provide data to calculate and analyse skills that are available and that are needed in the labour market, match individuals with jobs, and detect gaps in the labour market. As LinkedIn’s data and the possibilities it offers seem to be catching the public and policy attention (World Economic Forum 2016), how LinkedIn's algorithms operate to match individuals, skills and jobs becomes a macro and a political issue. The fact that platformization goes together with capitalization is often criticized to reinforce existing or even introducing new social inequalities in that various opportunities are tailor made depending on the individual's socio-economic status (Fourcade and Healy 2017). However, there is also a possibility of LinkedIn contributing to more equal opportunities on the labour market and consequently to social justice more generally. While it seems that LinkedIn has already constructed new and potentially challenging realities for many of the HE actors, it remains to be seen what Microsoft will do in the future with its LinkedIn service and an intersection of all digital platforms that it holds. 


\section{Acknowledgement}

I wish to thank Chris Muellerleile and Nick Lewis for their helpful comments in developing this paper; and to Susan Robertson and Roger Dale for their support in this research. The usual disclaimer applies. This paper was developed with the financial support of the European Commission FP7 People programme: Marie Curie Initial Training Network UNIKE (Universities in Knowledge Economies), grant agreement number 317452.

\section{References}

Agency for Science and Higher Education. 2017. Standards for the Evaluation of Quality of Universities and University Constituents in the Procedure of ReAccreditation of Higher Education Institutions. https://www.azvo.hr/images/stories/novosti/ENG_STANDARDS_FOR_THE_EV ALUATION_OF_QUALITY_-_UNIVERSITIES.pdf.

Andersson Schwarz, Jonas. 2017. "Platform Logic: An Interdisciplinary Approach to the Platform-Based Economy.” Policy and Internet 9 (4): 374-94.

Arvidsson, Adam, and Nicolai Peitersen. 2013. The Ethical Economy: Rebuilding Value After the Crisis. New York, NY: Columbia University Press.

Ashwin, Paul. 2015. "Missionary Zeal: Some Problems with the Rhetoric, Vision and Approach of the AHELO Project.” European Journal of Higher Education 5 (4): 437-44.

Baker, Forest. 2015. “LinkedIn: Helping Students and Schools Be Successdul - Forest Baker - NYU Torch Talk.” 2015. http://www.slideshare.net/forestbaker/linkedinhelping-students-and-schools-be-successdul-forest-baker-nyu-torch-talk/8.

Boden, Rebecca, and Maria Nedeva. 2010. “Employing Discourse: Universities and Graduate ‘Employability.”’ Journal of Education Policy 25 (1): 37-54.

Çalışkan, Koray, and Michel Callon. 2010. "Economization, Part 2: A Research Programme for the Study of Markets.” Economy and Society 39 (1): 1-32.

Cannon, Tom. 2015. "Unleashing LinkedIn for Education: An Interview with Charles Hardy.” Red Brick: Fresh Research Perspectives. 2015.

https://www.redbrickresearch.com/2015/09/24/unleashing-linkedin-for-educationan-interview-with-charles-hardy/. 
Chadha, Deesha, and James Toner. 2017. "Focusing in on Employability: Using Content Analysis to Explore the Employability Discourse in UK and USA Universities.” International Journal of Educational Technology in Higher Education 14 (33). https://doi.org/10.1186/s41239-017-0071-0.

Chawinga, Winner Dominic. 2017. “Taking Social Media to a University Classroom: Teaching and Learning Using Twitter and Blogs.” International Journal of Educational Technology in Higher Education 14 (3). https://doi.org/10.1186/s41239-017-0041-6.

Couldry, Nick, and Jose van Dijck. 2015. "Researching Social Media as If the Social Mattered.” Social Media + Society 1 (2): 1-7.

Dale, Roger, and Susan L. Robertson. 2012. “Toward a Critical Grammar of Education Policy Movements.” In Yearbook of Education 2012: Policy Borrowing and Lending in Education, edited by Gita Steiner-Khamsi and Florian Waldow, 21-40. London and New York: Routledge.

Darrow, Barb. 2017. “LinkedIn Claims Half a Billion Users.” Fortune. 2017. http://fortune.com/2017/04/24/linkedin-users/.

DfE. 2017. Teaching Excellence and Student Outcomes Framework Specification. London: Department for Education.

Fathom. 2012. "LinkedIn Advertising’s New Targeting Options a Higher-Ed Bonus.” 2012. http://www.fathomdelivers.com/blog/paid-media/linkedin-advertising-newtargeting-options-higher-education/.

Fourcade, Marion, and Kieran Healy. 2017. “Seeing like a Market.” Socio-Economic Review-Economic Review 15 (1): 9-29.

Fuchs, Christian. 2009. “A Contribution to the Critique of the Political Economy of the Internet.” Rethinking Marxism: A Journal of Economics, Culture \& Society 21 (3): 387-402.

Hazelkorn, Ellen. 2009. "Rankings and the Battle for World-Class Excellence: Institutional Strategies and Policy Choices.” Higher Education Management and Policy 21 (1).

Helmond, Anne. 2015. “The Platformization of the Web: Making Web Data Platform Ready." Social Media + Society 1 (2): 1-11. 
ICEF Monitor. 2015. “LinkedIn Rolls out New School Selection Services for Prospective Students.” 2015. http://monitor.icef.com/2015/01/linkedin-rolls-newschool-selection-services-prospective-students/.

Jobvite. 2016. Jobvite Recruiter Nation Report 2016. https://www.jobvite.com/wpcontent/uploads/2016/09/RecruiterNation2016.pdf.

Joly, Karine. 2016. “Say Goodbye to LinkedIn \#highered Rankings, Don’t Get Attached to Your University Page.” 2016.

http://collegewebeditor.com/blog/index.php/archives/2016/04/19/say-goodbye-tolinkedin-highered-rankings-dont-get-attached-to-your-university-page/.

Kelly, Marielle. 2016. Social Media for Your Student and Graduate Job Search. London: Palgrave.

Kjellberg, Sara, Jutta Haider, and Olof Sundin. 2016. “Researchers’ Use of Social Network Sites: A Scoping Review.” Library and Information Science Research 38 (3): 224-34.

Knight, Peter T., and Mantz Yorke. 2003. "Employability and Good Learning in Higher Education.” Teaching in Higher Education 8 (1): 3-16.

Komljenovic, Janja, Paul Ashwin, Jan Mcarthur, and Kayleigh Rosewell. 2018. “To Be or Not to Be Consumers: The Imperfect Alignment of English Higher Education Marketization Policy and the Narratives of First Year University Students.” In CGHE 2018 Annual Conference: The New Geopolitics of Higher Education. Centre for Global Higher Education. http://www.researchcghe.org/perch/resources/uk-sa-cg-paper-22.3.18.pdf.

Komljenovic, Janja, and Susan L. Robertson. 2016. “The Dynamics of 'MarketMaking' in Higher Education.” Journal of Education Policy 31 (5): 622-36.

Lackovic, Natasa, Roger Kerry, Rachael Lowe, and Tony Lowe. 2017. “Being Knowledge, Power and Profession Subordinates: Students’ Perceptions of Twitter for Learning.” Internet and Higher Education 33: 41-48.

Langley, Paul, and Andrew Leyshon. 2017. "Platform Capitalism: The Intermediation and Capitalisation of Digital Economic Circulation.” Finance and Society 3 (1): $11-31$.

LinkedIn. 2014. “LinkedIn Outcome Rankings Under the Hood.” 2014. 
_. 2015. “About Us - LinkedIn Newsroom.” 2015.

https://press.linkedin.com/about-linkedin.

2016. “Higher Education Resource Centre.” 2016.

https://university.linkedin.com/.

. 2017a. “Editing Your LinkedIn University Page - Overview.” 2017.

https://www.linkedin.com/help/lms/answer/40127/editing-your-linkedin-

university-page-overview?lang=en.

—_. 2017b. “University Lecturer.” 2017. https://www.linkedin.com/title/universitylecturer.

LinkedIn Corporation. 2012. “United States Securities Exchange Commission Annual Report Pursuant to Section 13 Ir 15(d) of the Securities Exchange Act of 1934 for the Fiscal Year Ended December 31, 2011. LinkedIn Corporation.”

_. 2013. "United States Securities Exchange Commission Annual Report Pursuant to Section 13 Ir 15(d) of the Securities Exchange Act of 1934 for the Fiscal Year Ended December 31, 2012. LinkedIn Corporation.”

_. 2014. "United States Securities Exchange Commission Annual Report Pursuant to Section 13 Ir 15(d) of the Securities Exchange Act of 1934 for the Fiscal Year Ended December 31, 2013. LinkedIn Corporation.” http://investors.linkedin.com/secfiling.cfm?filingID=1445305-14-439. 2015. "United States Securities Exchange Commission Annual Report Pursuant to Section 13 Ir 15(d) of the Securities Exchange Act of 1934 for the Fiscal Year Ended December 31, 2014. LinkedIn Corporation.”

. 2016. "United States Securities Exchange Commission Annual Report Pursuant to Section 13 Ir 15(d) of the Securities Exchange Act of 1934 for the Fiscal Year Ended December 31, 2015. LinkedIn Corporation.” https://s21.q4cdn.com/738564050/files/doc_financials/annual/2015/LinkedInAnnu alReport_2016.PDF.

Mackenzie, Adrian. 2018. “48 Million Configurations and Counting: Platform Numbers and Their Capitalization.” Journal of Cultural Economy 11 (1): 36-53. https://doi.org/10.1080/17530350.2017.1393443.

McCowan, Tristan. 2017. "Higher Education, Unbundling, and the End of the 
University as We Know It.” Oxford Review of Education 43 (6): 744-48.

Muellerleile, Chris. 2017. “'Platforming Market Space’, Presented at the Geographies of Markets Conference, Karl Polanyi Institute, Concordia University, Montreal, Quebec, 15-17 June 2017, Available from Author.”

Muniesa, Fabian, Liliana Doganova, Horacio Ortiz, Alvaro Pina-Stranger, Florence Paterson, Alaric Bourgoin, Véra Ehrenstein, et al. 2017. Capitalization: A Cultural Guide. Paris: Mines ParisTech.

Musson, Dave. 2016. “35 Gems of Inspiration from \#LinkedIn3D.” 2016. https://www.linkedin.com/pulse/35-gems-inspiration-from-linkedin3d-davemusson?trk=prof-post.

Nieh, Kylan. 2017. “Creating Your Resume Just Got a Whole Lot Easier with Microsoft and LinkedIn.” LinkedIn Official Blog. 2017. https://blog.linkedin.com/2017/november/8/Creating-your-resume-just-got-awhole-lot-easier-with-Microsoft-and-LinkedIn.

Nixon, Elizabeth, Richard Scullion, and Robert Hearn. 2016. "Her Majesty the Student: Marketised Higher Education and the Narcissistic (Dis)Satisfactions of the Student-Consumer.” Studies in Higher Education 43 (6): 927-43. https://doi.org/10.1080/03075079.2016.1196353.

Novet, Jordan. 2018. “LinkedIn Has Found a Way to Grow Its Recruiting Business since Joining Microsoft.” CNBC. 2018. https://www.cnbc.com/2018/02/14/jeffweiner-linkedin-found-a-way-to-grow-talent-solutions.html.

Oram, Andy, ed. 2001. Peer-to-Peer: Harnessing the Benefits of a Disruptive Technology. Sebastopol: O’Reilley.

Oxford Dictionary. 2016. “EBITDA.” 2016. https://en.oxforddictionaries.com/definition/EBITDA.

Pace, Justin. 2017. "How Universities Can Make the Most of the New LinkedIn University Pages.” 2017. http://blog.fullfabric.com/new-linkedin-university-pagestips-marketing-higher-education.

Ponterotto, Joseph G. 2006. “Brief Note on the Origins, Evolution, and Meaning of the Qualitative Research Concept 'Thick Description.”” The Qualitative Report 11 (3): 538-49. 
Prahalad, C. K., and Venkatram Ramaswamy. 2004. The Future of Competition: CoCreating Unique Value with Customers. Cambridge, MA: Harvard Business School Press.

Ritzer, G., and N. Jurgenson. 2010. "Production, Consumption, Prosumption: The Nature of Capitalism in the Age of the Digital 'Prosumer."' Journal of Consumer Culture 10 (1): 13-36.

Robertson, Susan L. 2019. "Comparing Platforms and the New Value Economy in the Academy.” In World Yearbook of Education 2019: Methodology in an Era of Big Data and Global Networks, edited by Radhika Gorur, Sam Sellar, and Gita Steiner-Khamsi. London and New York: Routledge.

Robertson, Susan L., and Janja Komljenovic. 2016. “Unbundling the University and Making Higher Education Markets.” In World Yearbook of Education 2016, The Global Education Industry, edited by Antoni Verger, Christopher Lubienski, and Gita Steiner-Khamsi, 211-27. London: Routledge.

Rutter, Richard, Stuart Roper, and Fiona Lettice. 2016. "Social Media Interaction, the University Brand and Recruitment Performance.” Journal of Business Research 69 (8): 3096-3104.

Schepp, Brad, and Debra Schepp. 2012. How to Find a Job on LinkedIn, Facebook, Twitter, Google+. Maidenhead: McGraw-Hill.

Shih, Clara. 2011. The Facebook Era : Tapping Online Social Networks to Market, Sell, and Innovate. 2nd ed. Upper Saddle River, N.J.: Prentice Hall.

Srnicek, Nick. 2017. Platform Capitalism. Cambridge, England ; Malden, Massachusetts: Polity.

Sum, Ngai Ling, and Bob Jessop. 2013. "Competitiveness, the Knowledge-Based Economy and Higher Education.” Journal of the Knowledge Economy 4 (1): 2444.

The Danish Accreditation Institution. 2013. Guide to Institutional Accreditation. http://akkr.dk/wp-content/filer/akkr/Guide-to-institutional-accreditation_final.pdf.

The Economist. 2016. “LinkedUp.” 2016. http://www.economist.com/news/businessand-finance/21700605-it-one-most-expensive-tech-deals-history-it-may-not-besmartest-making-sense. 
Voss, Krista Ann, and Anil Kumar. 2013. “The Value of Social Media: Are Universities Successfully Engaging Their Audience?” Journal of Applied Research in Higher Education 5 (2): 156-72.

Wagner, Kurt. 2015. “Three Reasons LinkedIn Broke the Bank for Lynda.Com.” Recode. 2015. http://recode.net/2015/04/09/three-reasons-linkedin-broke-the-bankfor-lynda-com/.

Weiner, Jeff. 2012. “The Future of LinkedIn and the Economic Graph.” 2012. https://www.linkedin.com/pulse/20121210053039-22330283-the-future-oflinkedin-and-the-economic-graph.

Williamson, Ben. 2015. “Algorithmic Skin: Health-Tracking Technologies, Personal Analytics and the Biopedagogies of Digitized Health and Physical Education.” Sport, Education and Society 20 (1): 133-51.

_. 2018. "The Hidden Architecture of Higher Education : Building a Big Data Infrastructure for the ' Smarter University .’” International Journal of Educational Technology in Higher Education 15 (12). https://doi.org/10.1186/s41239-0180094-1.

Wit, Karlijn De. 2014. “New to LinkedIn University Pages: Recommendations.” 2014. https://karlijndewit.wordpress.com/2014/05/12/new-to-linkedin-university-pagesrecommendations/.

World Economic Forum. 2016. The Human Capital Report 2016. Books. http://www3.weforum.org/docs/HCR2016_Main_Report.pdf.

Yorke, Mantz. 2006. Employability in Higher Education: What It Is - What It Is Not. York: The Higher Education Academy.

Yu, Ada. 2016. “Introducing the LinkedIn Students App.” LinkedIn Official Blog. 2016. https://blog.linkedin.com/2016/04/18/introducing-the-linkedin-students-app-helping-soon-to-be-colleg. 